\title{
Diagnostic Value of Contrast Enhanced Mammography in Detection of Cancer Breast
}

\author{
AHMED A. FAYAD, M.Sc.*; MOHAMED T. ABDELHAKK, M.D.** and HALA M. MAGHRABY, M.D.** \\ The Department of Radiodiagnosis, Bahia Hospital, Giza* and Faculty of Medicine for Girls, Al-Azhar University, \\ Cairo**, Egypt
}

\begin{abstract}
Background: Breast cancer in women is a major public health problem throughout the world. It is the most common cancer among women both in developed and developing countries.

Aim of Study: This study was undertaken to assess the diagnostic value of contrast enhanced mammography in detection of cancer breast.

Material and Methods: During the period from December 2015 to January 2017, 129 cases with 194 breast lesions in a prospective study presenting with various suspicious or equivocal lesions on mammography that underwent CEDM evaluation to test its diagnostic performance in the final diagnosis using the histopathology results as the gold standard of reference. The study includes 9 patients with past history of breast operations. Descriptive statisticswere used to analyze the data.

Results: There were 129 females (the ages ranged from 25-88 years with a mean 50 years) with 194 lesions. Of these lesions $162(83.5 \%)$ are malignant and $32(16.5 \%)$ are benign. The study demonstrated contrast enhancement in $91.9 \%$ of the malignant and $41 \%$ of the benign lesions. Contrast enhancement was observed in 136 malignant lesions. $22(14.9 \%)$ lesions of malignant lesions took homogenous enhancement and $114(77 \%)$ lesions took heterogeneous enhancement. In our study the margin of mass enhancing lesions showed illdefined and speculated margins were significantly higher in malignant lesions.

Conclusion: The use of dual energy contrast enhanced mammography technique can significantly improve the diagnostic quality and cancer detection rate.
\end{abstract}

Key Words: CEDM (contrast enhanced digital mammography).

\section{Introduction}

BREAST cancer in women is a major public health problem throughout the world. It is the most com-

Correspondence to: Dr. Ahmed A. Fayad,

The Department of Radiodiagnosis, Bahia Hospital, Giza, Egypt mon cancer among women both in developed and developing countries [1]. Breast cancer is the most common cancer among women in Egypt and is estimated to be the cause of $22 \%$ all cancer-related female deaths [2]. Early detection and diagnosis are essential for the prognosis and treatment of breast cancer [3]. Contrast-enhanced spectral mammography (CESM) is an adaptation of digital mammography that uses intravenous (IV) contrast to evaluate for breast cancer using a dual-energy technique [4]. CEM provides low-energy 2D mammographic images analogous to digital mammography and contrast-enhanced recombined images that allow assessment of neovascularity similar to that offered by MRI [5]. The potential clinical applications are the clarification of mammographically equivocal lesions, the detection of occult lesions on standard mammography, particularly in dense breast, the determination of the extent of disease, the assessment of recurrent disease and the monitoring of the response to chemotherapy [6]. By taking advantages of both mammography and breast MRI, contrast-enhanced digital mammography (CEDM) has emerged as a new promising imaging modality to improve efficacy of breast cancer screening and diagnosis [7].

\section{Material and Methods}

\section{Patients:}

129 patients referred from the outpatient clinics (after having a clinical breast examination) to the Radiology Department of Bahia Hospital in Egypt during the duration from December 2015 to January 2017 underwent CEDM evaluation to test its diagnostic performance in the final diagnosis using the histopathology results as the gold standard of reference. The ages ranged from 25-88 years with a mean 50 years. 
Contrast enhanced digital mammography technique:

Dual energy subtraction imaging exploits the energy dependence of X-ray attenuation through materials of different compositions in the breast, specifically iodine and soft tissues. A pair of lowand high-energy images is obtained after contrast and then the two images are combined to enhance areas of contrast uptake [8].

First, a cannula is inserted in the anticubital fossa on the opposite side of the affected breast. Intravenous injection of iodinated contrast agent was performed prior to patient positioning and breast compression to the seated patient; to avoid interference with the normal vascular dynamics of the breast. Patients received $1-1.5 \mathrm{ml}$ of contrast agent per kilogram of body weight at an injection speed of $3 \mathrm{ml} / \mathrm{sec}$, which is the same dose used for computed tomography. After the injection, the patient was disconnected from the injector. The cannula was left within the vein to provide a quick intravenous access in case of any idiosyncratic reaction.

Patient positioning and performance of $\mathrm{CE}$ digital mammography were no different from those of conventional mammography. Dual-energy CEDM was performed by acquiring a pair of lowand high-energy images in quick succession during a single breast compression. Compression is applied for all positions, in a way that is strong enough to limit breast motion but in the same time would not reduce blood flow.

Two minutes after the initiation of contrast medium injection, a set of bilateral craniocaudal (CC) and mediolateral oblique (MLO) views was acquired. The order of imaging is as followed: The cranio-caudal view of the unaffected breast followed by craniocaudal and medio-lateral oblique views of the affected breast; and then medio-lateral oblique view of the unaffected breast.

Low-energy images were acquired at peak kilo voltage $(\mathrm{kVp})$ values ranging from 26 to 31 , which is below the k-edge of iodine $(33.2 \mathrm{keV})$. Highenergy images were acquired at 45 to $49 \mathrm{kVp}$, which is above the k-edge of iodine. By subtraction of the 2 images through appropriate image processing, the visibility of the parenchyma is reduced and contrast-enhanced images are generated.

A research workstation was used for image analysis. All images were retrospectively evaluated by one breast radiologist with previous experience in mammography more than ten years. Images were read blind to patient history, clinical infor- mation and truth. To minimize bias risks from remembering cases.

\section{Statistical analysis:}

All data were analyzed SPSS 18.0 for windows (SPSS Inc., Chicago, IL, USA) and MedCalc 13 for windows (MedCalc Software bvba, Ostend, Belgium) Continuous variables were expressed as the mean \pm SD \& median (range), and the categorical variables were expressed as a number (percentage). Continuous variables were checked for normality by using Shapiro-Wilk test.

\section{Results}

Our study pool included 129 cases with 194 breast lesions in a prospective study presenting with various suspicious or equivocal lesions on mammography that underwent CEDM evaluation to test its diagnostic performance in the final diagnosis using the histopathology results as the gold standard of reference, The study includes 9 patients with past history of breast operations.

Patientsdemographics are summarized in Table (1), clinical presentations Table (2), anatomical location of the lesions Table (3). Diagnosis Table (4), the distribution of the final diagnoses within the "malignant lesion" group.

Table (1): Demographic data.

\begin{tabular}{ccc}
\hline & \multicolumn{2}{c}{$\begin{array}{c}\text { All studied patients } \\
(\mathrm{N}=129)\end{array}$} \\
\cline { 2 - 3 } Demographic data & \multicolumn{2}{c}{ No. } \\
\hline Age (years): & & \\
21-40 years & 25 & 19.4 \\
41-60 years & 76 & 58.9 \\
$>60$ years & 28 & 21.7 \\
Mean \pm SD & $50.07 \pm 11.15$ \\
Median (Range) & $49(25-88)$ \\
\hline
\end{tabular}

Table (2): Clinical presentations.

\begin{tabular}{lll}
\hline & \multicolumn{2}{c}{$\begin{array}{c}\text { All studied patients } \\
(\mathrm{N}=129)\end{array}$} \\
\cline { 2 - 3 } Clinical presentation & \multicolumn{2}{c}{ No. } \\
\hline Breast lump: & 15 & 11.6 \\
Absent & 5 & 3.8 \\
Mastalgia & 3 & 2.3 \\
Bleeding per nipple & 4 & 3.2 \\
Previous operation & 3 & 2.3 \\
Neo-adjuvant chemotherapy & & \\
Present & 114 & 88.4 \\
Routine screening: & & \\
Absent & 102 & 79.1 \\
Present & 27 & 20.9 \\
Family history & 15 & 11.6 \\
No family history & 12 & 9.3 \\
\hline
\end{tabular}


Table (3): Anatomical location of the lesions.

\begin{tabular}{ccc}
\hline \multirow{2}{*}{$\begin{array}{c}\text { Anatomical location of } \\
\text { the masses }\end{array}$} & \multicolumn{2}{c}{$\begin{array}{c}\text { All studied lesions } \\
(\mathrm{N}=194)\end{array}$} \\
\cline { 2 - 3 } & No. & $\%$ \\
\hline UOQ & 77 & 39.7 \\
LOQ & 35 & 18 \\
LIQ & 21 & 10.8 \\
LOQ & 18 & 9.3 \\
Central & 43 & 22.2 \\
\hline
\end{tabular}

Table (4): Diagnosis

\begin{tabular}{lcc}
\hline \multirow{2}{*}{ Diagnosis } & \multicolumn{2}{c}{$\begin{array}{c}\text { All studied lesions } \\
(\mathrm{N}=194)\end{array}$} \\
\cline { 2 - 3 } & \multicolumn{2}{c}{ No. } \\
\hline Contrast enhanced mammography: & & \\
$\quad$ Benign & 25 & 12.9 \\
$\quad$ Malignant & 169 & 87.1 \\
Histopathological: & & \\
$\quad$ Benign & & \\
$\quad$ Malignant & 32 & 16.5 \\
\hline
\end{tabular}

Table (5) comparison between benign tumors and malignant tumors as regard Contrast Enhanced Mammography: Primary sign to lesion Table (6). Comparison between benign tumors and malignant tumors as regard Contrast Enhanced Mammography: Secondary sign to lesion Table (7).

Table (5): The distribution of the final diagnoses within the "malignant lesion" group.

\begin{tabular}{|c|c|c|}
\hline & \multicolumn{2}{|c|}{$\begin{array}{l}\text { Malignant lesions } \\
\qquad(\mathrm{N}=162)\end{array}$} \\
\hline & No. & $\%$ \\
\hline Invasive ductal carcinoma & 126 & 77.8 \\
\hline Invasive lobular carcinoma & 15 & 9.3 \\
\hline Adenocarcinoma & 8 & 4.9 \\
\hline Papillary carcinoma & 4 & 2.5 \\
\hline Mucinous carcinoma & 9 & 5.5 \\
\hline
\end{tabular}

Table (6): Comparison between benign tumors and malignant tumors as regard Contrast Enhanced Mammography: Primary sign to lesion.

\begin{tabular}{|c|c|c|c|c|c|c|}
\hline \multirow[t]{2}{*}{$\begin{array}{l}\text { Primary sign } \\
\text { of mass }\end{array}$} & \multicolumn{2}{|c|}{$\begin{array}{l}\text { Benign } \\
\text { tumors } \\
(\mathrm{N}=32)\end{array}$} & \multicolumn{2}{|c|}{$\begin{array}{c}\text { Malignant } \\
\text { tumors } \\
(\mathrm{N}=162) \\
\end{array}$} & \multirow[t]{2}{*}{ Test $\$$} & \multirow[t]{2}{*}{$\begin{array}{l}p \text {-value } \\
\text { (Sig.) }\end{array}$} \\
\hline & No. & $\%$ & No. & $\%$ & & \\
\hline \multicolumn{7}{|l|}{ Size: } \\
\hline$<2 \mathrm{~cm}$ & 9 & 28.1 & 72 & 44.4 & 2.934 & 0.231 \\
\hline $2-5 \mathrm{~cm}$ & 19 & 59.4 & 75 & 46.3 & & (NS) \\
\hline$>5 \mathrm{~cm}$ & 4 & 12.5 & 15 & 9.3 & & \\
\hline \multicolumn{7}{|l|}{ Margin: } \\
\hline Smooth & 22 & 68.8 & 7 & 4.3 & 98.293 & $<0.001$ \\
\hline Indistinct & 10 & 31.3 & 37 & 22.8 & & (HS) \\
\hline Spiculated & 0 & 0 & 118 & 72.8 & & \\
\hline
\end{tabular}

Pattern of

enhancement:

\begin{tabular}{lllllll} 
No enhancement & 27 & 58.7 & 12 & 8.1 & $18.606<0.001$ \\
Homogenous & 13 & 28.3 & 22 & 14.9 & (HS) \\
Heterogenous & 6 & 13 & 114 & 77 & & \\
Calcification: & & & & & & \\
Absent & 24 & 75 & 133 & 82.1 & 0.872 & 0.350 \\
Present & 8 & 25 & 29 & 17.9 & (NS) \\
Absent & 24 & 75 & 133 & 82.1 & $24.056<0.001$ \\
Microcalcification & 0 & 0 & 24 & 14.8 & (HS) \\
Macrocalcification & 8 & 25 & 5 & 3.1 & & \\
\hline
\end{tabular}

Table (7): Comparison between benign tumors and malignant tumors as regard Contrast Enhanced Mammography: Secondary sign to lesion.

\begin{tabular}{|c|c|c|c|c|c|c|}
\hline \multirow[t]{2}{*}{$\begin{array}{l}\text { Secondary sign } \\
\text { to mass }\end{array}$} & \multicolumn{2}{|c|}{$\begin{array}{l}\text { Benign } \\
\text { tumors } \\
(\mathrm{N}=30)\end{array}$} & \multicolumn{2}{|c|}{$\begin{array}{l}\text { Malignant } \\
\text { tumors } \\
(\mathrm{N}=106)\end{array}$} & \multirow[t]{2}{*}{ Test } & \multirow[t]{2}{*}{$\begin{array}{c}p \text {-value } \\
\text { (Sig.) }\end{array}$} \\
\hline & No. & $\%$ & No. & $\%$ & & \\
\hline \multicolumn{7}{|l|}{$D P A:$} \\
\hline Absent & 25 & 83.3 & 94 & 88.7 & 0.611 & 0.531 \\
\hline Present & 5 & 16.7 & 12 & 11.3 & & (NS) \\
\hline \multicolumn{7}{|l|}{ Skin thickening: } \\
\hline Absent & 26 & 86.7 & 78 & 73.6 & 2.224 & 0.136 \\
\hline Present & 4 & 13.3 & 28 & 26.4 & & $(\mathrm{NS})$ \\
\hline \multicolumn{7}{|l|}{$\begin{array}{l}\text { Associated } \\
\text { axillary LN: }\end{array}$} \\
\hline Absent & 23 & 76.7 & 27 & 25.5 & 26.360 & $<0.001$ \\
\hline Present & 7 & 23.3 & 79 & 74.5 & & (HS) \\
\hline
\end{tabular}




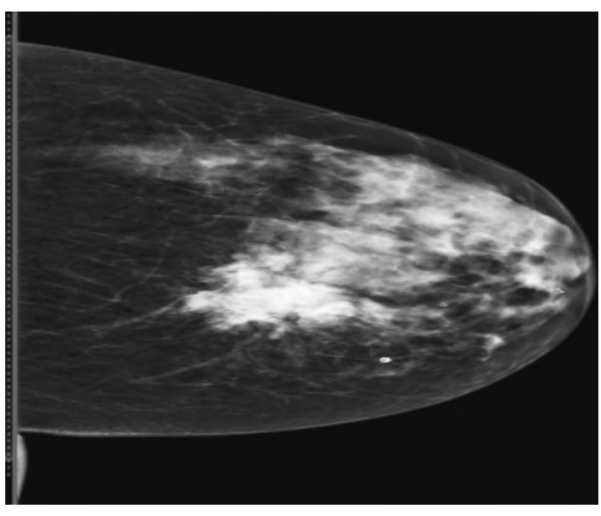

(A): LT CC without contrast.

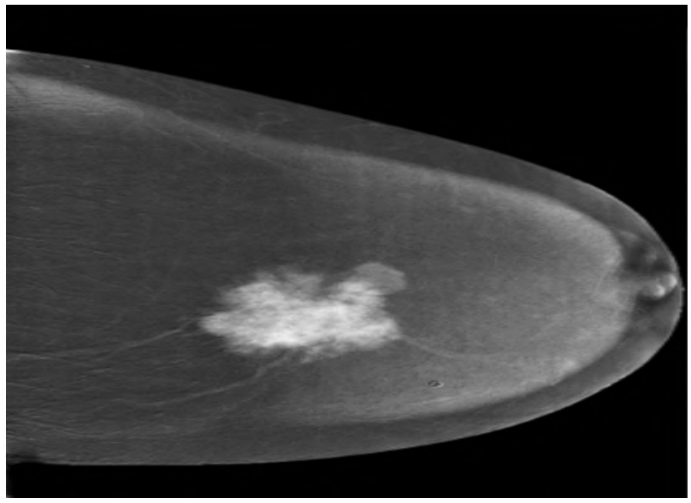

(C): LT CC with contrast.

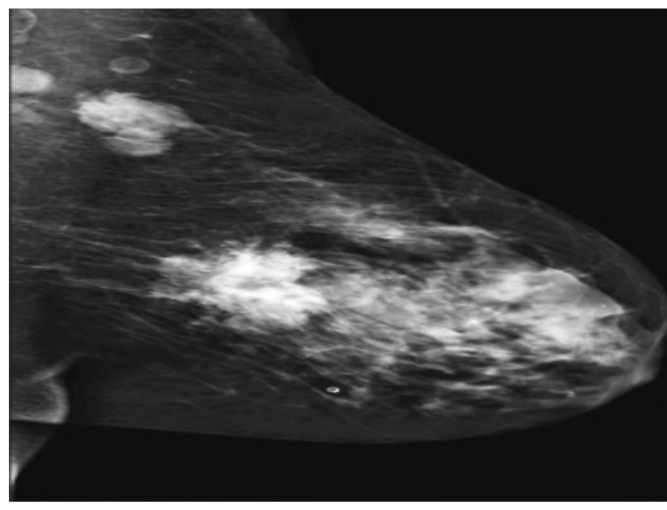

(B): LT MLO without contrast.

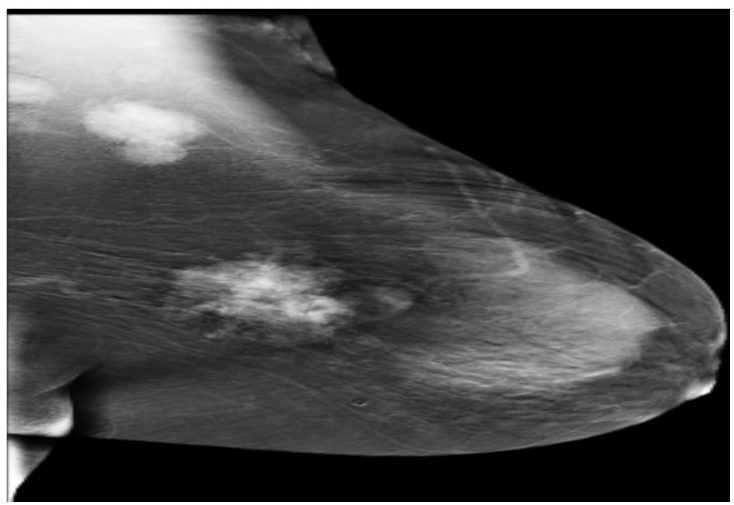

(D): LT MLO with contrast.

Fig. (1): 34 years old female presented by left breast lump. Mammography (CC and MLQ views (A\&B) presented Irregular spiculated dense masses at the UOQ. Contrast enhanced Mammography (Fig. C\&D) These mass shows contrast enhancement criteria suggesting malignancy, histopathology confirm the diagnosis (Invasive ductal carcinoma grade III).

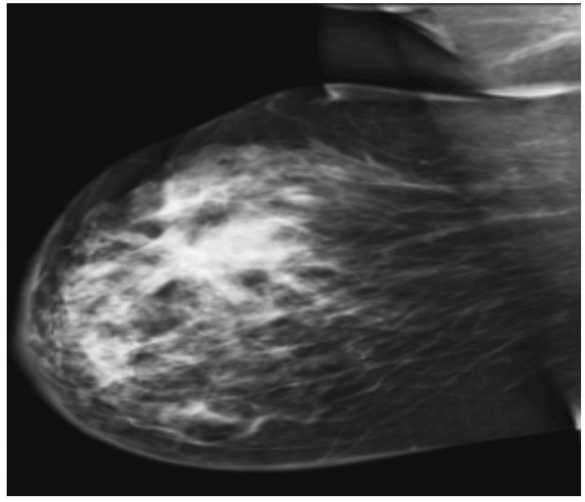

RT CC without contrast.

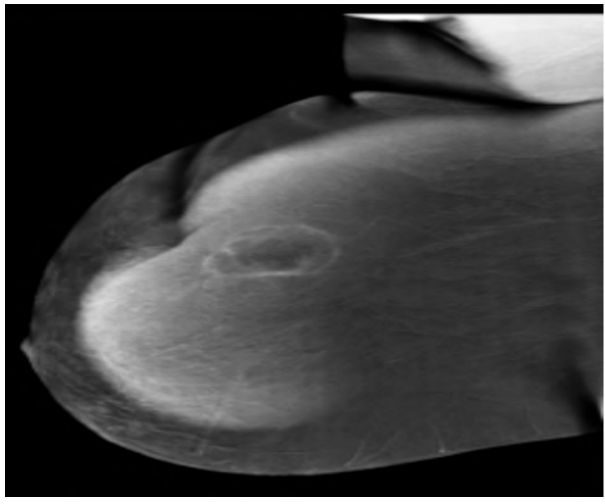

RT MLO with contrast.

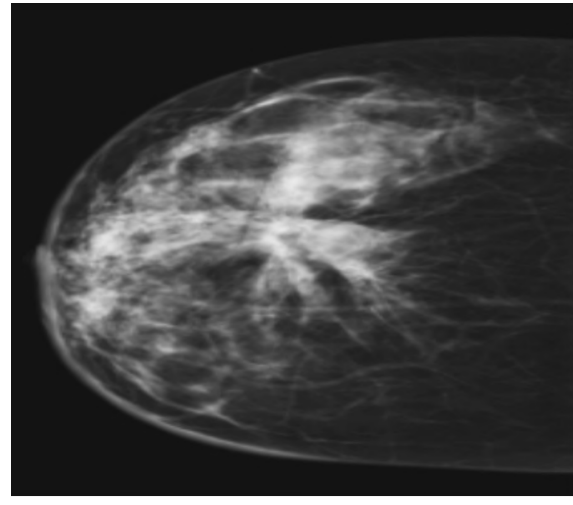

RT MLO without contrast.

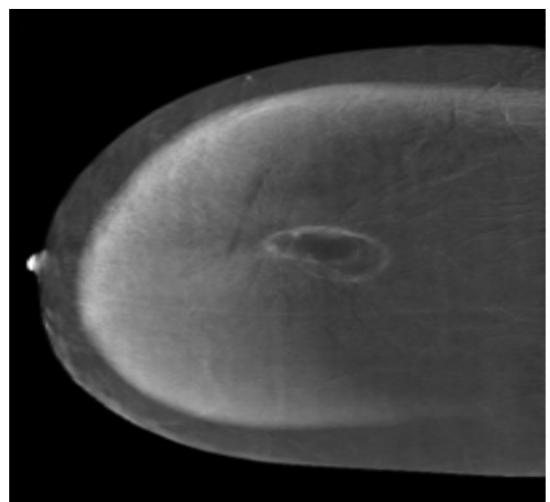

RT CC with contrast.

Fig. (2): 45 years old female presenting with possible recurrence at the conservative breast surgery scar (invasive ductal carcinoma grade III). Mammography presented suspected are of irregular borders seen at the site of the previous operation. Contrast enhanced mammography showed enhancement of the lesion findings suggesting malignancy, histopathology confirm the diagnosis (Post operative recurrence). 


\section{Discussion}

Breast cancer is the second leading cause of cancer deaths in women today and the most common cancer in women [9]. CESM is a promising imaging technique, which provides information from standard digital mammography combined with enhancement characteristics related to underlying neoangiogenesis [10]. Our study pool included 129 cases with 194 breast lesions in a prospective study presenting with various suspicious or equivocal lesions on mammography that underwent CEDM evaluation to test its diagnostic performance in the final diagnosis using the histopathology results as the gold standard of reference. Mammography (MX) has some limitations, such as lesions masked by normal fibroglandular tissue, lesions seen on only one view, and subtle architectural distortions [11]. CESM has been reported to offer improved sensitivity, specificity, and accuracy compared with conventional mammography [10] By taking advantages of both mammography and breast MRI, contrast-enhanced digital mammography (CEDM) has emerged as a new promising imaging modality to improve efficacy of breast cancer screening and diagnosis [7].

For contrast enhanced mass lesions, morphology assessment was expected to yield a high diagnostic accuracy. We characterized the enhancement pattern, the degree of enhancement, the margins and the shape of enhancing mass lesions in order to select the best diagnostic features to differentiate between benign and malignant breast pathologies. Because not only malignant breast lesions showed contrast uptake, we had to analyze the morphologic characteristics and enhancement patterns in an attempt to narrow the differential diagnosis and decrease the number of false positive cases.

In our study the CEDM showed a sensitivity of $98.1 \%$ with specificity of $68.8 \%$, the low specificity is attributed to number of false positive cases (10 cases). These cases showed contrast uptake pattern, these enhancement patterns raised the suspicion of malignant nature however biopsy were pathologically proved periductal mastitis, fibrocystic disease and post-operative enhancing granulation tissue.

In the current study, the enhancement pattern of the mass lesions that showed contrast uptake was classified, into homogeneous and heterogeneous pattern of contrast uptake. Homogeneous enhancement is confluent and uniform. Heterogeneous enhancement is non-uniform with areas of variable contrast uptake. A heterogeneous pattern of contrast uptake was characteristic for malignant mass lesions and a homogeneous pattern was characteristic for benign ones (! 0.001). In our study contrast enhancement was observed in 136 out of the 148 $(91.9 \%)$ malignant lesions. $22(14.9 \%)$ lesions of malignant lesions took homogenous enhancement and 114 (77\%) lesions took heterogeneous enhancement.

Usually, breast cancers manifest as irregularly shaped non circumscribed masses, with or without micro-calcifications [12]. We confirmed this in the current study where the description of the mass shape was the most predictive feature for malignancy on CEDM, it showed a sensitivity of $80.52 \%$ and a specificity of $71.43 \%$ (LR+: 2.82 and LR-: $0.27)$. In the current study the margin of mass enhancing lesions showed ill defined and speculated margins were significantly higher in malignant lesions.

We also observe that CEDM has the advantage of being reproducible without operator dependency. Moreover, CEDM is a fast imaging technique and subtracted images have a direct correlation with conventional mammograms.

The present study hints that, similar to breast MRI, CEDM could be of particular interest for the assessment of the extent of disease. Indeed, our study has shown that CEDM detected multifocal breast cancers in all cases. The dual-energy technique offers the possibility of imaging both breasts in two views (CC and MLO) during a single injection of contrast medium and so to perform a bilateral CEDM examination versus Diekmann, et al., which use temporal method which only one view per breast can be acquired for a single injection of contrast medium.

We observe the easy way we use for dual energy Contrast-enhanced digital mammography technique that can be performed by using a current digital mammography system with some specific software and hardware adaptations for acquisition and image processing. Especially in the case of equivocal mammography and ultrasound assessments. In this potential indication CEDM has the advantage of being a fast imaging technique with immediate availability in the mammography suite without a new appointment and without loss of time.

The results of this preliminary clinical trial suggest that dual-energy CEDM has a higher diagnostic accuracy for the detection of breast carcinoma. CEDM may be useful for the assessment of the extent of disease as well as the clarification of equivocal, multicentric, multifocal lesions and post 
operative follow-up. These results encourage further investigations to define the place of CEDM among the other breast imaging methods in particular in comparison to breast MRI.

\section{Conclusion:}

Contrast-enhanced digital mammography is a new breast imaging technique using full-field digital mammography in conjunction with the injection of an iodinated contrast medium. Dualenergy CEDM also allows shorter acquisition duration and does not require prolonged breast compression. This could result in better acceptance from patients and fewer technical problems.

\section{References}

1- ZEENELDIN A.A.1, RAMADAN M., GABER A.A., et al.: Clinico-pathological features of breast carcinoma in elderly Egyptian patients: A comparison with the nonelderly using population-based data. J. Egypt Natl. Canc. Inst. Mar., 25 (1): 5-11, 2013.

2- BRUNI L., L. BARRIONUEVO-ROSAS, G. ALBERO, et al.: ICO Information Centre on HPV and Cancer (HPV Information Centre). Human Papillomavirus and Related Diseases in Egypt. 2017.

3- WANG, KANGAN LI, LIHUI WANG, et al.: Preclinical study of diagnostic performances of contrast-enhanced spectral mammography versus MRI for breast diseases in China. Springerplus, 5 (1): 763, 2016.

4- JORDANA PHILLIPS, JENNIFER STEINKELER, KOMAL TALATI, ALEXANDER BROOK, PRISCILLA J. SLANETZ and TEJAS S. MEHTA: Workflow Considerations for Incorporation of Contrast-Enhanced Spectral Mammography Into a Breast Imaging Practice, Journal of the American College of Radiology, 2018.
5- MATTHEW F., PIZZITOLA1, ROXANNE LORANS1, BARBARA A., DONALD W., CATHERINE M. and BHAVIKA K.: The Future of Contrast-Enhanced Mammography, American Journal of Roentgenology, Volume 210, Issue 2, 2018.

6- DROMAIN C., HIBAULT F., MULLER S., et al.: Dualenergy contrast-enhanced digital mammography: Initial clinical results. European Radiology, 21 (3): 565-574, 2011.

7- GOPICHANDH DANALA, FARANAK AGHAEI, MORTEZA HEIDARI, TERESA WU, BHAVIKA PATEL and BIN ZHENG: Computer-aided classification of breast masses using contrast-enhanced digital mammograms Feb., 2018.

8- DROMAIN C. and BALLEYGUIER C.: ContrastEnhanced Digital Mammography. In Bick U., Diekmann F., Digital mammography. Springer-Verlag Berlin Heidelberg, 187-198, 2010.

9- KATHERINE R. BIRCHARD, KIRAN REDDY BUSIREDDY and RICHARD C. SEMELKA: Breast imaging in: Critical Observations in Radiology for Medical Students, 10: 201-224, 2015.

10- BHAVIKA K. PATEL, SARA RANJBAR, TERESA WU, BARBARA A. POCKAJ, JING LI PHDC NAN ZHANG, MARK LOBBES, BIN ZHANG and J. ROSS MITCHELL: Computer-aided diagnosis of contrast-enhanced spectral mammography: A feasibility study, European Journal of RadiologyVolume 98, January, Pages 207-213, 2018.

11- HUMPHREY L.L., HELFAND M., CHAN B.K. and WOOLF S.H.: Breast cancer screening: A summary of the evidence for the US Preventive Services Task Force. Ann. Intern. Med., 137: 347-360, 2014.

12- YOO J.L., WOO O.H., KIM Y.K., et al.: Can MR Imaging contributes in characterizing well-circumscribed breast carcinomas? Radiographics, 30 (6): 1689-702, 2010.

\section{القيمة التشخيصية للتصوير بالأشعة الرقمية بالصبغة الصفية

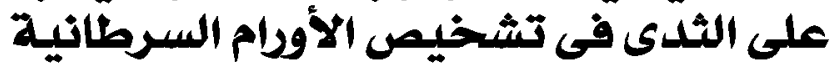

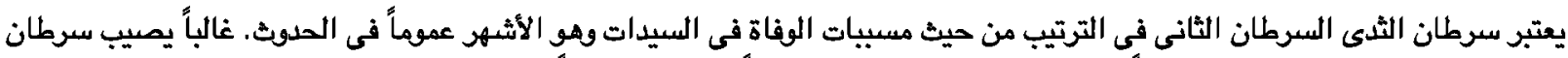

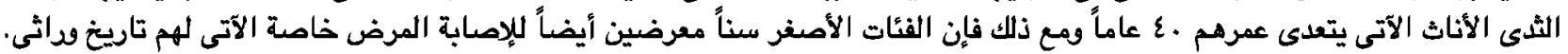

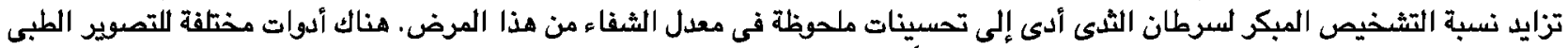

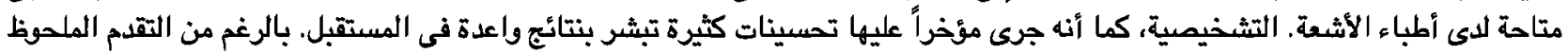

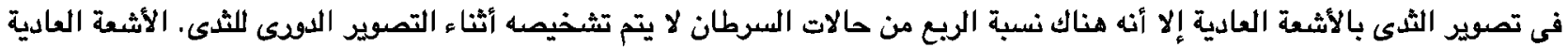

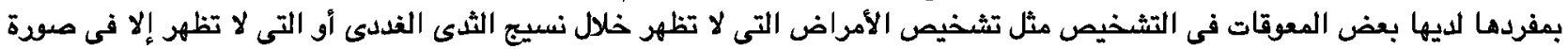

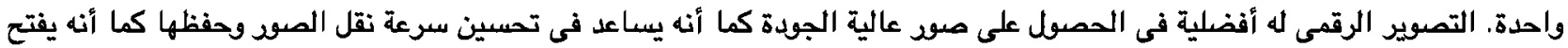

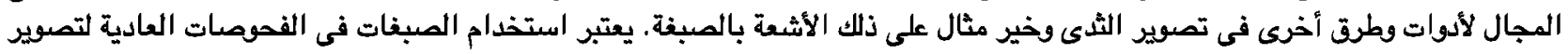

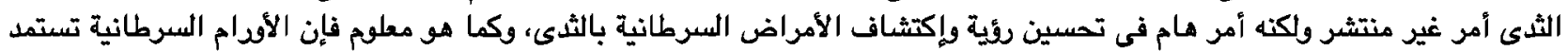

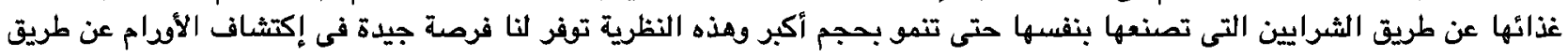

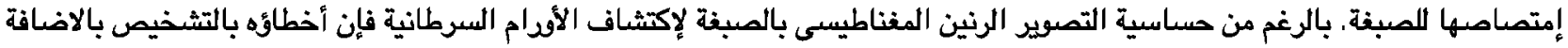

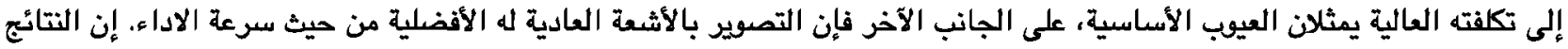

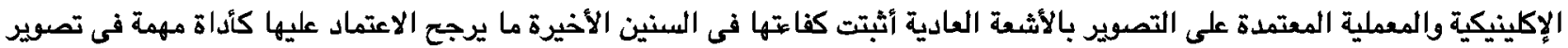

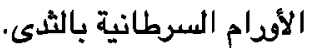

